A integração das formações superficiais na modelação e cartografia do risco geormorfológico: o caso da Serra do Marão António de Sousa Pedrosa, Andreia Pereira

\title{
A INTEGRAÇÃO DAS FORMAÇÕES SUPERFICIAIS NA MODELAÇÃO E CARTOGRAFIA DO RISCO GEORMORFOLÓGICO: O CASO DA SERRA DO MARÃO
}

\section{The integration of slope deposits in the modeling and mapping of natural hazards: The case of Sierra Marão}

\author{
António de Sousa Pedrosa \\ Departamento de Geografia, FLUP, CEGOT \\ Bolsista CAPES \\ Porto - Portugal \\ aspedros@gmail.com \\ Andreia Pereira \\ Departamento de Geografia, FLUC, CEGOT \\ Porto - Portugal \\ andreiaflup@gmail.com
}

Artigo recebido para publicação em 14/07/2011 e aceito para publicação em 05/12/2011.

RESUMO: $\quad$ Na região Noroeste de Portugal, as vertentes de maior declive das áreas montanhosas de substracto granítico e xistento reúnem, frequentemente, características propícias à ocorrência de movimentos em massa, particularmente deslizamentos, fluxos de detritos e processos complexos. Entre os factores de ordem biogefísica que potenciam a probabilidade de ocorrência de movimentos em massa nestes relevos vigorosos destacam-se as suas características estruturais, geológicas e morfológicas.

Incidindo sobre as especificidades resultantes deste contexto geomorfológico e climático, o presente trabalho pretende contribuir para o aperfeiçoamento da modelação computacional dos movimentos em massa e para um maior rigor na avaliação da susceptibilidade geográfica da sua ocorrência. Esta avaliação multi-factorial da susceptibilidade face aos movimentos em massa é precursora na investigação portuguesa ao nível da integração computacional sistematizada das formações superficiais, enquanto condicionante de extrema importância para a evolução dinâmica das vertentes.

Ainda que o papel das formações superficiais seja amplamente reconhecido pela geomorfologia dinâmica, a verdade é que a inexistência de elementos cartográficos, seja em formato analógico ou digital, tem inibido a sua inclusão nos modelos desenvolvidos em sistemas de Informação geográfica - SIG, traduzindo-se na sua insuficiente acuidade.

Visando contribuir para superar esta lacuna, o trabalho de investigação aqui sintetizado partiu da identificação e georreferenciação das formações superficiais presentes nas vertentes da Serra do Marão, designadamente depósitos de vertente periglaciares e tardiglaciares, mantos de alteração e, ainda, depósitos fluvio-aluvionares.

Uma vez constituida uma base de dados espacial com a s características das formações superficiais levantadas no terreno, procedeu-se a uma correlação ponderada com os demais factores seleccionados, tendo como objectivo último a cartografia rigorosa da susceptibilidade face aos movimentos em massa na serra do Marão

Palavras-chave: Montanhas. Geomorfologia. Formações superficiais. Riscos naturais. SIG. 
A integração das formações superficiais na modelação e cartografia do risco geormorfológico: o caso da Serra do Marão António de Sousa Pedrosa, Andreia Pereira

ABSTRACT: The mountainous alignments that cross Northern Portugal in a longitudinal direction combine a rough relief with very steep slopes and an exceptionally high average yearly rainfall (superior to $2000 \mathrm{~mm}$ ). These slopes are often regularized by surface formations, which correspond to weathering mantles on granite and quaternary deposits produced by periglacial processes, the last ones more frequent over schist.

Mass movements, especially debris flows and landslides, are frequently recorded in this territory, playing a crucial role in slope dynamics. The Marão Hill is a tectonic relief, mostly constituted by metamorphic rocks, with deeply entrenched valleys and accented slopes, where the surface formations have a strong presence. Aiming to show the absolute need of considering these formations in mass movement risk assessment, a field research was developed in Marão Hill, where was completed its exhaustive survey, georeferenciation and representation in a Geographical Information System. Then it was conducted a correlated spatial analysis, with a weighted overlay of the permanent conditioning factors considered more relevant, besides surface formations, within this territorial context, particularly lithology, slope, slope aspect and vegetation cover.

The results show a major difference between the two hazard maps produced, by including or neglecting the surface for mations. The risk-prone sites identified matches the areas that combine strong slopes, north quadrant orientation and the presence of surface formations, particularly the ones from the tardiglacial period, characterized by less cohesion and bigger heterometry.

Keywords: Mountains. Geomorphology. Slope deposits. Natural hazards. GIS

\section{INTRODUÇÃO}

Na região Noroeste de Portugal, as vertentes de maior declive das áreas montanhosas de substrato granítico e xistento reúnem, frequentemente, características propícias à ocorrência de movimentos em massa, particularmente deslizamentos, fluxos de detritos e processos complexos.

Entre os factores de ordem biogeofísica que potenciam a probabilidade de ocorrência de movimentos em massa nestes relevos vigorosos destacam-se as suas características estruturais, geológicas e morfológicas. $\mathrm{Na}$ área de estudo em análise, a Serra do Marão, merecem especial ênfase o grau de alteração das rochas granitóides; os contactos litológicos entre xistos e granitos; a existência de uma densa rede de fracturação; bem como disponibilidade de material detrítico mais ou menos desagregado, frequentemente acumulado em mantos de alteração, depósitos de vertente, escombreiras de gravidade e depósitos fluvio-aluvionares. Acrescem ainda as condições de drenagem superficial e sub-superficial e as implicações resultantes de diferentes tipos de coberto vegetal e uso do solo.
Esta susceptibilidade territorial é agravada pelos elevados quantitativos de precipitação que se verificam na designada Barreira de Condensação do Noroeste Português, alinhamento montanhoso, sensivelmente paralelo à linha de costa, onde a pluviosidade média anual chega a ser superior aos $2000 \mathrm{~mm}$ e a exceder os $3000 \mathrm{~mm}$ nos pontos mais altos do Gerês. Este sistema montanhoso, onde se enquadra o Marão, é atingido durante os meses de Outono e Inverno pela sucessiva passagem das perturbações frontais, sendo igualmente afectado por chuvas orográficas não negligenciáveis. Deste modo, quer os valores de precipitação acumulada, quer os quantitativos resultantes de chuvas concentradas no tempo e no espaço são assinaláveis.

A distribuição da precipitação no maciço estruturalmente definido da Serra do Marão apresenta um padrão globalmente decrescente de Noroeste para Sudeste, localmente diferenciado por questões oro-morfológicas, designadamente pelas variações altitudinais, pela exposição das vertentes às direcções dominantes das precipitações frontais e orográficas e pela influência dos vales abertos a sudoeste, condicionados pela orogenia alpina. Em Peso Régua, localizada a Este da barreira 
de condensação no domínio micro-climático do vale do Douro, registam-se precipitações médias anuais na ordem dos $800 \mathrm{~mm}$, valor situado no espectro das normais climáticas de feição mediterrânica. Por influência do vale do Tâmega, que permite a progressão das massas de ar húmido para Leste, a precipitação média anual em Amarante não excede os $1100 \mathrm{~mm}$. Os obstáculos morfológicos, que obrigam à ascensão das massas de ar, justificam os valores médios de $3000 \mathrm{~mm}$, registados na estação pluviométrica de Lamas de Olo, localizada numa área de topo aplanada.

Incidindo sobre as especificidades resultantes deste contexto geomorfológico e climático, o presente trabalho pretende contribuir para o aperfeiçoamento da modelação computacional dos movimentos em massa e para um maior rigor na avaliação da susceptibilidade geográfica da sua ocorrência. Nesse sentido, ambiciona produzir sinergias com a cartografia dos riscos geomorfológicos, instrumento essencial ao ordenamento do território.

Esta avaliação multi-factorial da susceptibilidade face aos movimentos em massa é precursora na investigação nacional ao nível integração computacional sistematizada das formações superficiais, enquanto condicionante de extrema importância para a evolução dinâmica das vertentes.

Ainda que o papel das formações superficiais seja amplamente reconhecido pela geomorfologia dinâmica, a verdade é que a inexistência de elementos cartográficos, seja em formato analógico ou digital, tem inibido a sua inclusão nos modelos desenvolvidos em Sistemas de Informação Geográfica - SIG, traduzindo-se na sua insuficiente acuidade.

Visando contribuir para superar esta lacuna, o trabalho de investigação aqui sintetizado partiu da identificação e georreferenciação das formações superficiais presentes nas vertentes da Serra do Marão, designadamente depósitos de vertente periglaciares e tardiglaciares, mantos de alteração e, ainda, depósitos fluvio-aluvionares.

Uma vez constituída uma base de dados espacial com as características das formações superficiais levantadas no terreno, procedeu-se a uma correlação ponderada com os demais factores seleccionados, tendo como objectivo último a cartografia rigorosa da susceptibilidade face aos movimentos em massa na Serra do Marão.

\section{CARACTERIZAÇÃO GEO-ESTRUTURAL DA ÁREA DE ESTUDO.}

A Serra do Marão constitui um dos mais vigorosos elementos morfológicos que se podem individualizar no grande alinhamento montanhoso que separa o Noroeste de Portugal dos planaltos transmontanos. Este conjunto de serras e planaltos elevados constitui, pela sua altitude como pela sua massa (DIAS, 1949) um obstáculo que determina uma transformação muito rápida do carácter atlântico das paisagens.

O Marão corresponde à elevação tectónica, por movimentos terciários e quaternários, do Maciço Antigo. O soco pré-câmbrico, fracturado pela orogenia hercínica de orientação NW-SE sofre posterior acção tectónica tardi-hercínica, responsável pelas falhas de orientação NNE-SSW, que assumem especial importância na área mais oriental desta serra. A orogenia alpina, de orientação dominante NE-SW, virá a provocar o rejogo das falhas hercínicas e tardi-hercínicas, originando ainda as importantes falhas que condicionam diversos vales que atravessam o Marão, designadamente os rios Tâmega e Ovil, sendo responsável pelo sooerguimento deste maciço montanhoso (PEREIRA, RIBEIRO, 1983; PEDROSA, 1993).

A estrutura geológica nesta área do maciço antigo é particularmente complexa em termos litológicos, estratigráficos e tectónicos (Figura 1). Ela deve a sua originalidade geológica à presença de afloramentos de terrenos ordovícicos e silúricos que contactam a leste com o chamando complexo xisto-grauváquico ante-ordovícico e, a oeste, com os granitos hercínicos porfiróides de grão grosseiro essencialmente biotíticos, vulgarmente designados por "granitos de Amarante" (RIBEIRO et al., 1962).

As rochas mais antigas correspondem ao complexo xisto-grauváquico ante-ordovícico do grupo do Douro, composto fundamentalmente por duas formações autóctones (Bateiras e Ervedosa) e por três formações alóctones (Rio Pinhão, Pinhão e Desejosa) (SOUSA, 1982). Comprova-o a existência de acidentes sin-sedimentares responsáveis pela repetição de unidades. No topo da sequência apresentada encontra-se a formação de S. Domingos que corresponderá a um período de grande perturbação tectónica na bacia correspondente à designada discordância da fase Sarda (PEREIRA, 1987). 
As três formações que mais directamente nos interessam são a formação de Pinhão, Desejosa e Domingos. As rochas destas três formações são as mais antigas da área, atribuindo-se-lhe a idade câmbrica com base em correlações regionais e no facto da fonte alimentadora das correntes de turbidez ser a plataforma câmbrica situada a NE, E e SE da bacia onde se depositaram os materiais que constituem o complexo xisto-grauváquico do Grupo do Douro (SOUSA, 1982).

Os terrenos ordovícicos assentam em discordância estratigráfica sobre os anteriores e iniciam-se por um conglomerado muito grosseiro e poligénico. Este conglomerado corresponderia ao início da transgressão Ordovícica em mar pouco profundo, apresentando-se heterogéneo considerando o grau de rolamento dos materiais assim como a matriz que os agrega (RIBEIRO, et al., 1962).

Distinguem-se duas formações de idade Ordovícica: a formação de quartzito armoricano e a formação de Pardelhas (PEREIRA, 1989). A primeira é formada fundamentalmente pela alternância de quartzitos e xistos cinzentos, enquanto que a segunda, que assenta sobre a anterior, inicia-se por rochas de tipo filitos e xistos micáceos com intercalções de metassilitos, evoluindo para filitos e xistos cinzento-azulados e, por fim, para xistos ardosíferos. A sua espessura é variável devido às intensas deformações que sofreu ao longo da história geológica.

Os terrenos Silúricos ocupam uma área significativa da Serra do Marão e tal como os do Ordovícico apresentam diversos tipos de fácies. Pereira (1987) distingue a formação de Campanhó onde as litofácies representadas são típicas do Silúrico, datadas do Landoveriano ao Ludloviano e a formação de Santos, de difícil datação já que os geólogos não dispõem de elementos biocronológicos que o permitam fazer. No entanto, o mesmo autor, em correlação com outros locais reporta-as ao Silúrico Superior ou, mais provavelmente ao Devónico inferior.

As unidades que temos vindo a fazer referência são consideradas como autóctones. Foram, no entanto, identificadas unidades parautóctones e alóctones separadas todas elas por carreamentos.

As parautóctones correspondem às unidades de Canadelo e Monquim. A primeira pode subdividir-se em diversas subunidades, sendo a inferior caracterizada pelos xistos carbonosos com intercalações de ampelitos, liditos e quartzitos, enquanto a superior se caracteriza por uma sequência rítmica negativa, típica de turbiditos (PEREIRA, 1989). No que se refere à unidade de Monquim, esta pode-se dividir em duas subunidades, das quais a inferior mostra perfeita correspondência com a formação de Campanhó e a superior com a de Santos.

Figura 1: Cartografia geo-estrutural da Serra do Marão.

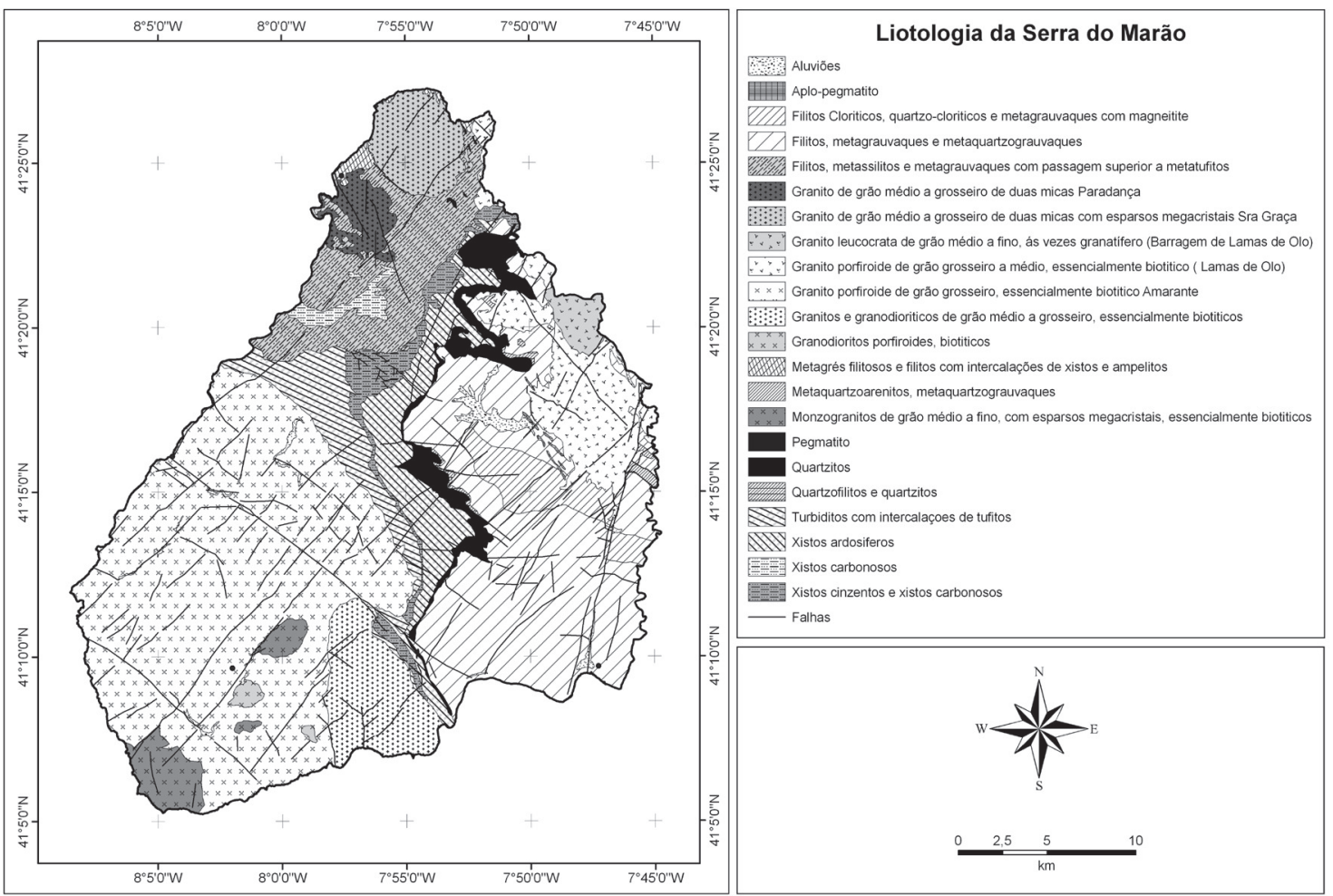

Soc. \& Nat., Uberlândia, ano 23 n. 3, 529-544, set/dez. 2011 
Os terrenos alóctones na área, correspondem à unidade de Vila Nune que é constituída na base por quartzitos, seguindo-se os vulcanitos e por fim os xistos essencialmente pelíticos.

Devido à posterior intrusão dos granitos houve uma faixa de rochas ordovícico-silúricas que sofreram uma forte acção de metamorfismo de contacto. Desta forma originou-se uma orla de corneanas, xistos quiastolíticos e xistos mosqueados. Este tipo de rochas salientam-se pela sua importante dureza, sendo de realçar as corneanas, que se apresentam muito resistentes aos agentes da geodinâmica externa. A sua localização está relacionada com a existência dos granitos, cuja intrusão é responsável pelas transformações das rochas pré-existentes, originando auréolas de metamorfismo.

As rochas granitóides apresentam características diversificadas, pelo que se impõe uma breve referência à sua génese e composição químico-mineralógica para melhor se compreenderem as implicações que poderão ter no aparecimento de movimentos em massa.

Nesta área, encontram-se representados os três grupos dos granitos hercínicos, da Zona Centro Ibérica. O granito de duas micas situa-se na parte Norte da Serra do Marão e corresponde aos batólitos de Paradança e da Sra. da Graça, formando maciços de contorno subcircular que intruem a zona central dos mantos de carreamento, sendo caracterizados pelo predomínio da moscovite e de granularidade média a grosseira. A Este da área considerada no estudo surge o maciço compósito de Vila Real que se caracteriza por ser um granito porfiróide de grão grosseiro a médio, essencialmente biotítico. Segundo Pereira (1989) encontra-se muito deformado por cisalhamentos dextros. Importa ainda referir os aplitos pelos relevantes reflexos geomorfológicos que possuem nesta área e que são dominantemente albíticos, por vezes, com granadas.

No entanto, os granitos mais comuns são aqueles que se englobam nos granitóides essencialmente biotíticos. De idade hercínica e de génese crustal profunda, são sin a tardi tectónicos relativamente à última fase desta orogenia (F3) correspondendo à série intermédia da zona de cisalhamento de Vila Nova de Cerveira-Amarante.
No seio desta grande mancha de granitos surgem afloramentos de outros tipos de rochas granitóides, com características um pouco diferentes das anteriores, fundamentalmente no que se refere à granularidade, já que a composição química é idêntica. Por vezes, apresentam reflexos geomorfológicos importantes nomeadamente ao nível do desenvolvimento da rede hidrográfica e da génese e evolução de algumas depressões.

\section{INTERPRETAÇÃO GEOMORFOLÓGICA: CARACTERIZAÇÃO DOS FACTORES DE SUSCEPTIBILIDADE.}

\section{As formações superficiais: os depósitos de vertente herdados do frio.}

Os processos morfogenéticos do passado condicionam de modo indubitável a actual dinâmica de vertentes. Os processos operantes durante a última grande glaciação permitiram o desenvolvimento de formações superficiais que ainda hoje regularizam muitas das vertentes no Norte do País (PEDROSA, 1993, 1994 ${ }^{\mathrm{a}}$, 2001; PEDROSA et.al., 2001; PEDROSA, MARTINS, 2001). Estas assumem hoje um papel decisivo na ocorrência de movimentos em massa, o maior risco geomorfológico presente na Serra do Marão.

A seguinte coluna estratigráfica (Figura 2) procura resumir de modo abrangente a evolução de vertentes na Serra do Marão nos últimos 30.000 anos, associando a descrição de cada nível aos processos principais pela sua formação (PEDROSA, et.al., 2007). 
A integração das formações superficiais na modelação e cartografia do risco geormorfológico: o caso da Serra do Marão António de Sousa Pedrosa, Andreia Pereira

Figura 2: Coluna estratigráfica das formações superficiais na Serra do Marão.

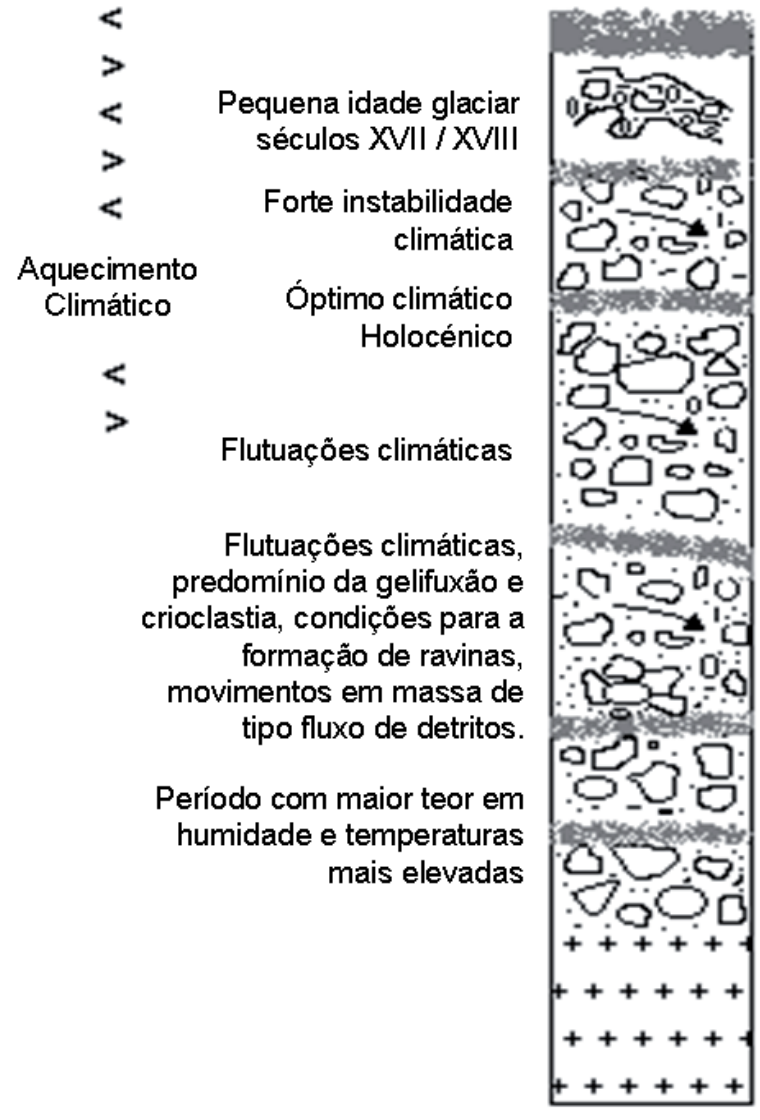

Dos depósitos mais recentes, o que se apresenta no início série é anterior a 28000 BP. É um depósito muito heterométrico, onde se individualizam grandes blocos e reduzidas quantidades de material arenoso e argiloso; características que nos permitem concluir que na sua génese se encontram a processos de tipo solifluxivo. Simultaneamente, teriam de se verificar ciclos de gelo/degelo que facilitariam a fracturação das rochas, bem como condições climáticas que permitissem o transporte dos materiais através de solifluxões. A fusão das neves durante a época mais quente do ano permitiria a acumulação de grandes quantidades de água o solo.

Entre os $28440 \pm 490 \mathrm{BP}$ e os $22160 \pm 490 \mathrm{BP}$ o clima deverá ter sofrido um aquecimento que terá permitido a pedogénese. Assim, é plausível a hipótese da colonização das vertentes pela vegetação, permitindo que estas chegassem a um estado de equilíbrio dinâmico. O paleossolo referido encontra-se fossilizado por novos depósitos de vertente do tipo solifluxivo,

\section{Solo actual}

Erosão de solos por escorrência superficial

Paleossolo $2830+/$ - 50 BP

Sub-Boreal - Formação da Lameira

Paleossolo 8000 BP

Depósitos solifluxivos

movimentos em massa

paleoravinamentos

Covelo do Monte

\section{Paleossolo $15550 \mathrm{BP}$ \\ Gelifluxões/solifluxões Depósitos estratificados \\ Paleoravinamentos \} de vertente}

Paleossolo $21340+/-350$ BP

Depósitos solifluxivos

\section{Paleossolo $28440+/-490$ BP}

Depósitos glaciares (?) depósito solifluxivo

da fácies inferior da formação de Muas

o que poderá traduzir um pequeno arrefecimento climático e o recrudescimento dos processos erosivos. A vegetação que havia conquistado as vertentes situadas a maiores altitudes poderá ter parcialmente desaparecido, expondo as rochas à acção do gelo.

Segue-se, novamente, uma fase climática favorável à pedogénese, como comprovado pela datação por C14 de um paleossolo com uma idade compreendida entre os $21340 \pm 350$ BP. Uma vez mais, se verifica o avanço da vegetação para altitudes mais elevadas, colonizando as vertentes e protegendo-as dos processos erosivos.

Os depósitos estratificados de vertente de cariz periglaciar, que fossilizam este último paleossolo, relacionam-se com a última fase do Würm. A quantidade de vestígios que chegaram até aos nossos dias evidencia a importância deste período na evolução das vertentes na Serra do Marão.

$\mathrm{Na}$ fase terminal da última grande glaciação, o clima deveria caracterizar-se por um frio relativamente seco, permitindo vários ciclos gelo/degelo, 
potenciando a gelifracção das rochas e o transporte por gelifluxão dos materiais resultantes. (DAVEAU, 1973,1978; REBELO, 1986; CORDEIRO, 1986, 1988; PEDROSA, 1993, 1994'). A vegetação seria muito escassa, podendo mesmo não existir nas altitudes mais elevadas, onde se encontraria a rocha a nu, sujeita aos processos de crioclastia. A existência de "coiffes" (VALADAS, 1984) permite concluir que o processo fundamental de transporte dos materiais ao longo das vertentes se fazia por gelifuxão.

A análise de diversas formações demonstra, contudo, que coexistiam outros processos, nomeadamente ravinamentos. Os vestígios de paleo-ravinamentos visíveis em alguns depósitos comprovam a existência de condições para o desenvolvimento destas formas. Outros depósitos, pelas suas características, evidenciam a possibilidade de terem ocorrido movimentos do tipo fluxo de detritos, que movimentariam grandes quantidades de material de uma forma relativamente rápida.

Seguir-se-ia uma fase em que o clima terá evoluído rapidamente para temperaturas mais amenas (CORDEIRO, 1990) e para maiores quantidades de precipitação, levando a alterações profundas na dinâmica das vertentes, passando a predominar a acção da escorrência e da dinâmica fluvial, em detrimento dos processos relacionados com a acção do gelo. Não possuímos, para esta área, nenhuma prova efectiva que corrobore esta afirmação, mas é globalmente aceite que o início do Tardiglaciar se terá verificado pelos $15550 \mathrm{BP}$, caracterizando-se por uma rápida subida das temperaturas, facto que se deve ter mantido até próximo dos $12000 \mathrm{BP}$, seguido de uma nova crise climática pelos 11000 BP (CORDEIRO, 1990; GUILLIEN et al., 1978; NONN, 1966; VLIRT-LANÖE, 1988; GARMENDIA, 1988).

Não encontramos vestígios na serra do Marão que permitam separar de um modo indubitável os depósitos do Pleniglaciar Würmiano do Tardiglaciar (PEDROSA, 1993, 1994'). Apenas as características micromorfológicas nos fornecem algumas indicações acerca dos depósitos que poderão corresponder já ao Tardiglaciar, pois os materiais que neles se encontram não apresentam sinais de terem sido transportados por acção do gelo, e, por outro lado, apresentam características heterométricas bem pronunciadas, não identificáveis com depósitos estratificados de vertente típicos do Pleniglaciar würmiano. O clima deste período deveria permitir a fragmentação das rochas por acção do gelo, mas apenas em altitudes elevadas, onde existiriam ainda alguns afloramentos rochosos desprovidos de qualquer cobertura. No entanto, a característica fundamental deste clima seria a queda de neve durante um período do ano, e o degelo desta, coincidente com o aumento das temperaturas, provavelmente acompanhado de pluviosidade.

Esta alteração climática terá permitido solifluxões mais ou menos generalizadas que levaram à regularização de grande parte das vertentes da área, aspecto que se manteve até aos nossos dias. Por outro lado, ter-se-ão reunido condições propícias à ocorrência de fluxos de detritos de grandes dimensões, de que encontramos vestígios nos fundos de alguns vales. $\mathrm{O}$ Tardiglaciar teve importantes implicações na evolução das vertentes da Serra do Marão, tendo sido responsável pela movimentação e transporte de muito material que havia resultado de processos morfogenéticos anteriores. Parte deste material foi levado para fora da região através da dinâmica fluvial e outra parte foi retido na área, entulhando fundos de valeiros e regularizando a maioria das vertentes (REBELO, 1975; REBELO; PEDROSA, 1993). Deste modo, protegeu a rocha in situ da actuação de diversos processos morfogenéticos e promoveu a fixação da vegetação, minimizando o impacto dos processos erosivos. Apesar da instalação de determinadas comunidades vegetais, isso não se traduziu no desenvolvimento de solos muito profundos. Estes são quase sempre esqueléticos, estando sujeitos a desaparecerem ao mínimo desequilíbrio que possa eventualmente ocorrer.

Pelos 8000 BP existiram novamente condições climáticas propícias à pedogénese, correspondendo ao óptimo climático holocénico (GOUDIE, 1979). De facto, encontramos um paleossolo num depósito de vertente cuja datação por $\mathrm{C} 14$ permite inferir esta conclusão. As temperaturas registaram uma subida, permitindo o desenvolvimento da vegetação, o que acontecia mesmo em altitudes elevadas, desde que existissem condições para a formação de um solo, mesmo que pouco desenvolvido.

O chamado óptimo holocénico terá tido o seu fim próximo dos $5000 \mathrm{BP}$, altura em que se inicia o 
sub-boreal (GOUDIE, 1979), o qual se caracterizou por um ligeiro arrefecimento. (DAVEAU, 1988).

$\mathrm{O}$ recrudescimento dos processos erosivos durante este período não se deve à alteração das condições climáticas, mas sim à actividade do homem (JORDA et al., 1980), que na serra do Marão estaria ligada à criação de animais através da pastorícia. Esta actividade implicaria muitas vezes a prática de queimadas para a obtenção e renovação da vegetação, o que expunha o solo a determinados processos erosivos, nomeadamente ao impacto das gotas de chuva e à escorrência. Em alguns locais existem indícios que sustentam a hipótese de que os processos associados à acção da escorrência se manifestavam de forma acentuada, sendo responsáveis pelo transporte de material ao longo das vertentes. Esta dinâmica erosiva estaria, provavelmente, relacionada com as altitudes mais elevadas, com a rarefacção da vegetação e, ainda, com a exposição a Norte das vertentes.

As escombreiras de gravidade identificadas nas vertentes do Marão associam-se a uma macro-gelifracção das rochas, correspondendo a sua génese a diversos períodos que activaram a sua formação e evolução.

Algumas delas regularizam vertentes, por vezes com fortes declives, e podem encontrar-se a partir dos 700 metros de altitude, como por exemplo no vale da ribeira de Leigido. Relacionam-se, muitas vezes, com vertentes sombrias, voltadas ao quadrante Norte. Uma fase importante para a origem destas formas poderá ter sido a pequena idade glaciar, veri- ficada nos séculos XVII e XVIII (PEDROSA, 1994하). Nesta altura, os locais mais elevados onde a rocha se encontrava à superfície seriam afectados pela acção do gelo, indutora da fragmentação, alimentando as escombreiras de gravidade (PEDROSA, 1991, 1992). Ainda hoje, este fenómeno está activo em algumas vertentes sombrias, onde a rocha aflora sem cobertura de solo e de vegetação (PEDROSA, 1993, 1994a).

\section{Análise dos declives enquanto factor condicionante da susceptibilidade aos movimentos em massa.}

Aproximadamente $50 \%$ da área em estudo apresenta declives superiores a $18 .^{\circ}$ (Tabela 1). Na verdade, a presença de declives elevados ou muito elevados na Serra do Marão é um factor de primeira ordem para a ocorrência de movimentos em massa. Os declives que apresentam maior representatividade correspondem à classe dos $18^{\circ}-30^{\circ}$, com uma expressão de $39 \%$, seguindo-se a classe dos $11^{\circ}-18^{\circ}$. Diversos estudos realizados sobre a dinâmica de vertentes e os riscos geomorfológicos na Região Norte, apontam os declives compreendidos entre os $18 .^{\circ}$ a $45 .^{\circ}$ como sendo aquele que implicam uma maior susceptibilidade para a ocorrência de movimentos em massa. Essa susceptibilidade torna-se ainda mais forte quando muitas dessas vertentes apresentam depósitos de tipo periglaciar ou tardiglaciar nas áreas de xisto, ou mantos de alteração nas rochas granitóides.

Tabela 1: Distribuição dos declives na Serra do Marão

\begin{tabular}{|l|r|r|}
\hline Declive (graus) & Área (ha) & $\%$ \\
\hline $0-2$ & 7275.03 & 9.06 \\
\hline $2-8$ & 4798.93 & 5.98 \\
\hline $8-11$ & 6497.32 & 8.09 \\
\hline $11-18$ & 21318.99 & 26.55 \\
\hline $18-30$ & 30998.99 & 38.61 \\
\hline $30-45$ & 8374.42 & 10.43 \\
\hline $45-60$ & 679.53 & 0.85 \\
\hline $60-80$ & 237.32 & 0.30 \\
\hline $80-90$ & 109.47 & 0.14 \\
\hline
\end{tabular}

Soc. \& Nat., Uberlândia, ano 23 n. 3, 529-544, set/dez. 2011 


\section{A exposição de vertentes e a preponderância de} ocorrência de movimentos em massa.

A análise da exposição das vertentes (Tabela 2) revela-se, de igual modo, essencial, na medida em que quando conjugadas com os fortes declives da área e com a distribuição das formações superficiais condicionam o aparecimento e o desenvolvimento de processos geomorfológicos específicos (PEDROSA 1993; REBELO, 2007).

Múltiplos trabalhos têm demonstrado que as vertentes voltadas aos quadrantes Norte $(\mathrm{NW}, \mathrm{N}$, $\mathrm{NE}$ ) são aquelas que, em termos naturais, facilitam o aparecimento de movimentos em massa, em virtude da conservação de humidade no solo.

Tabela 2: Distribuição das exposições de vertente na Serra do Marão

\begin{tabular}{|l|r|r|}
\hline \multicolumn{1}{|c|}{ Orientação } & Área (ha) & \% \\
\hline N & 7702.66 & 9.59 \\
\hline NE & 6623.82 & 8.25 \\
\hline E & 7791.29 & 9.70 \\
\hline SE & 10295.31 & 12.82 \\
\hline S & 9991.40 & 12.44 \\
\hline SW & 9830.47 & 12.24 \\
\hline W & 10780.51 & 13.43 \\
\hline NW & 10232.01 & 12.74 \\
\hline Slorientação & 7042.59 & 8.77 \\
\hline
\end{tabular}

Implicações do uso do solo na susceptibilidade aos movimentos em massa.

À diversidade estrutural e geomorfológica descrita, corresponde também uma grande diversidade de uso funcional do solo da área em estudo (Tabela 3 ).

Tabela 3:Distribuição do uso do solo na Serra do Marão

\begin{tabular}{|c|c|c|}
\hline Uso do solo & Área (ha) & $\%$ \\
\hline Áreas Urbanas & 2320.46 & 2.89 \\
\hline Outras áreas agrícolas & 12059.56 & 15.02 \\
\hline Sistemas culturais complexos & 7080.26 & 8.82 \\
\hline Vinha & 4335.72 & 5.40 \\
\hline Outras áreas florestais & 2285.58 & 2.85 \\
\hline Povoamento de Carvalhos & 721.30 & 0.90 \\
\hline Povoamento de Pinheiro Bravo & 11212.88 & 13.97 \\
\hline Floresta Mista & 10332.92 & 12.87 \\
\hline Povoamento de Eucalipto & 918.84 & 1.14 \\
\hline Vegetaçäo arbustiva e subarbustiva & 23141.57 & 28.82 \\
\hline Áreas ardidas & 4558.70 & 5.68 \\
\hline Rocha a nu & 1248.66 & 1.56 \\
\hline Outros usos & 73.5429 & 0.09 \\
\hline
\end{tabular}


As áreas agrícolas ocupam 29,24\% podendo distinguir-se os sistemas culturais complexos $(8,8 \%)$ onde a prática da irrigação é quase uma constante e uma área especializada de cultura da vinha $(5,4 \%)$ inserida quase toda na RDD, onde encontramos diversos problemas relacionados com a erosão de solos provenientes das novas técnicas de armação da vinha (PEDROSA, 1994; ; PEDROSA et.al, 2004). Os outros sistemas agrícolas correspondem quase sempre a uma agricultura de subsistência sem grandes recursos técnicos e ainda baseado no tradicional sistemas de socalcos tradicional no Norte do País.

Finalmente temos uma área importante de matos e espaços de vegetação degradada $(28,8 \%)$ que corresponde em grande medida ás áreas centrais do conjunto serrano de altitude mais elevada. Coincidem também com áreas de xisto onde os solos se apresentam muitas vezes esqueléticos. Apesar de apresentarem diversos problemas em termos de erosão de vertentes, não se relacionam com os processos específicos tratados neste trabalho.

As áreas florestais predominantes relacionam-se fundamentalmente com povoamento puros de Pinheiros Bravos (Estado) ou, então com a denominada floresta mista associada a pequenas propriedades particulares.

\section{METODOLOGIA.}

Desenvolvendo os procedimentos metodológicos adoptados, importa esclarecer os factores biogeofísicos condicionantes da ocorrência de movimentos em massa considerados na análise de correlação geo-espacial realizada (PEDROSA; PEREIRA, 2008). Assim, tendo em linha de conta as características geomorfológicas da área em estudo, já descritas em detalhe, foram integrados na análise os factores litologia, declive, exposição das vertentes, ocupação do solo e, por fim, a existência de formações superficiais, classificadas em função da sua idade geológica, processo de formação, tipo de material, grau de desagregação ou meteorização e espessura ou profundidade da formação. A uma outra escala de análise, de maior pormenor, justificar-se-ia ainda a inclusão de informação relativa à rede de falhas e fracturas e ao perfil longitudinal das vertentes, especificando a presença de uma morfologia côncava ou convexa.

$\mathrm{O}$ trabalho de campo foi fundamental para de- terminar a distribuição e caracterização das formações superficiais, coadjuvado com a utilização de um GPS sub-métrico que possibilitou a sua definição precisa.

O recurso à tecnologia SIG permitiu a constituição de uma base de dados georreferenciada que agrega as características de todos os elementos relevantes à análise em causa, com especial ênfase para as propriedades do substrato litológico georreferenciado à escala 1:50.000 e para a classificação de uso do solo à escala 1:25.000, discriminada em função das tipologias tecido urbano, área agrícola e especificidades culturais, área florestal e espécies arbóreas dominantes, formações arbustivas e subarbustivas, citando as que possuem maior expressão territorial. Os instrumentos de análise bidimensional e tridimensional do terreno, oferecidos pelas aplicações SIG, permitiram ainda a produção da cartografia de declives segundo uma quadrícula de $25 \mathrm{~m}^{2}$ e a geração do mapa de exposição de vertentes.

Uma vez produzidos os diferentes níveis de informação cartográfica já referidos - litologia, declives, exposições, formações superficiais e uso do solo - procedeu-se à reclassificação interna de cada um destes, definindo-se o risco inerente a cada classe. Por fim, a cartografia da susceptibilidade de ocorrência de movimentos em massa resultou da correlação ponderada dos mapas físicos temáticos reclassificados.

Passamos a explicitar em detalhe as opções técnico-científicas por de trás do processo avaliação geo-espacial da susceptibilidade realizado com recurso à aplicação ARCGIS 9.3.

Os declives surgem como o factor com maior peso relativo (33\%), afectando-se a classe de risco mais elevado às vertentes com mais de $18 .^{\circ}$ de inclinação.

No quadro das formações superficiais, segundo condicionante mais valorizado na análise de correlação ponderada, as classes de risco mais elevado correspondem aos depósitos de vertente periglaciares e tardiglaciares, seguindo-se-lhe os mantos de alteração granítica mais intensa, nomeadamente no granito de Paradança e da Sra. da Graça; cujas características quimíco-mineralógicas, granulométricas e de fracturação potenciaram uma alteração mais forte e em maior profundidade (PEDROSA, 1993). O granito de Amarante, apesar de nalguns locais se encontrar fortemente arenizado, apresenta uma menor componente argilosa, determinado menor grau de susceptibilidade ao desenvolvimento de movimentos em massa (Figura 3). 
Dada a dificuldade em avaliar com precisão e de forma sistematizada o grau de risco associado aos diferentes usos do solo, procurou-se não atribuir um peso globalmente excessivo (18\%), a fim de não enviesar os resultados. Naturalmente, que os usos do solo aos quais foi assignada uma classificação de risco mais elevado são aqueles que representam um distúrbio mais significativo ao equilíbrio dinâmico das vertentes. Em consonância com este princípio, foi atribuído o grau máximo às ocupações do solo que implicam alterações morfológicas do terreno induzidas pela acção antrópica. Entre estas destacam-se as áreas ocupadas pela vinha, particularmente a vinha em patamares, em virtude da fragmentação dos afloramentos de xisto e/ou remeximento do solo e materiais detríticos, da alteração do perfil das vertentes e da modificação dos processos de drenagem.

As culturas de regadio são, de igual modo, consideradas um uso de incremento da susceptibilidade, por via da saturação dos solos. Por fim, as reflorestações recentes, por implicarem significativas movimentações edáficas, por vezes com recurso a maquinaria pesada, podem constituir uma condição favorável ao despoletar de movimentos em massa.
A exposição de vertentes e as características litológicas não foram consideradas como factores determinantes, mas sim como condições de agravamento de uma susceptibilidade já confirmada. Assim atribuímos uma percentagem de $15 \%$ e $12 \%$ respectivamente.

A menor relevância atribuída ao substrato litológico da vertente, ou seja, às propriedades da rocha-mãe, deve-se à importância superlativa que as formações superficiais possuem.

Defendemos que, no Maciço Antigo, o papel preponderante das formações superficiais (depósitos periglaciares e tardiglaciares, escombreiras de gravidade e mantos de alteração) na ocorrência dos movimentos em massa, acaba por minimizar a influência da litologia.

Anotada esta importante ressalva analítica, importa referir que atribuímos uma maior ponderação às rochas granitóides, uma vez que os diferentes tipos de xistos e quartzitos, não apresentando neste domínio morfogenético mantos de alteração, pelo que não possuem qualquer influência no surgimento de movimentos em massa. No que concerne às exposições de vertente consideramos as voltadas aos quadrantes Norte $(\mathrm{NW}, \mathrm{N}$, $\mathrm{NE)}$ como as que apresentam maior susceptibilidade, já que registam maiores índices de humidade.

Figura 3: Distribuição das formações superficiais na Serra do Marão, segundo classificação simplificada.

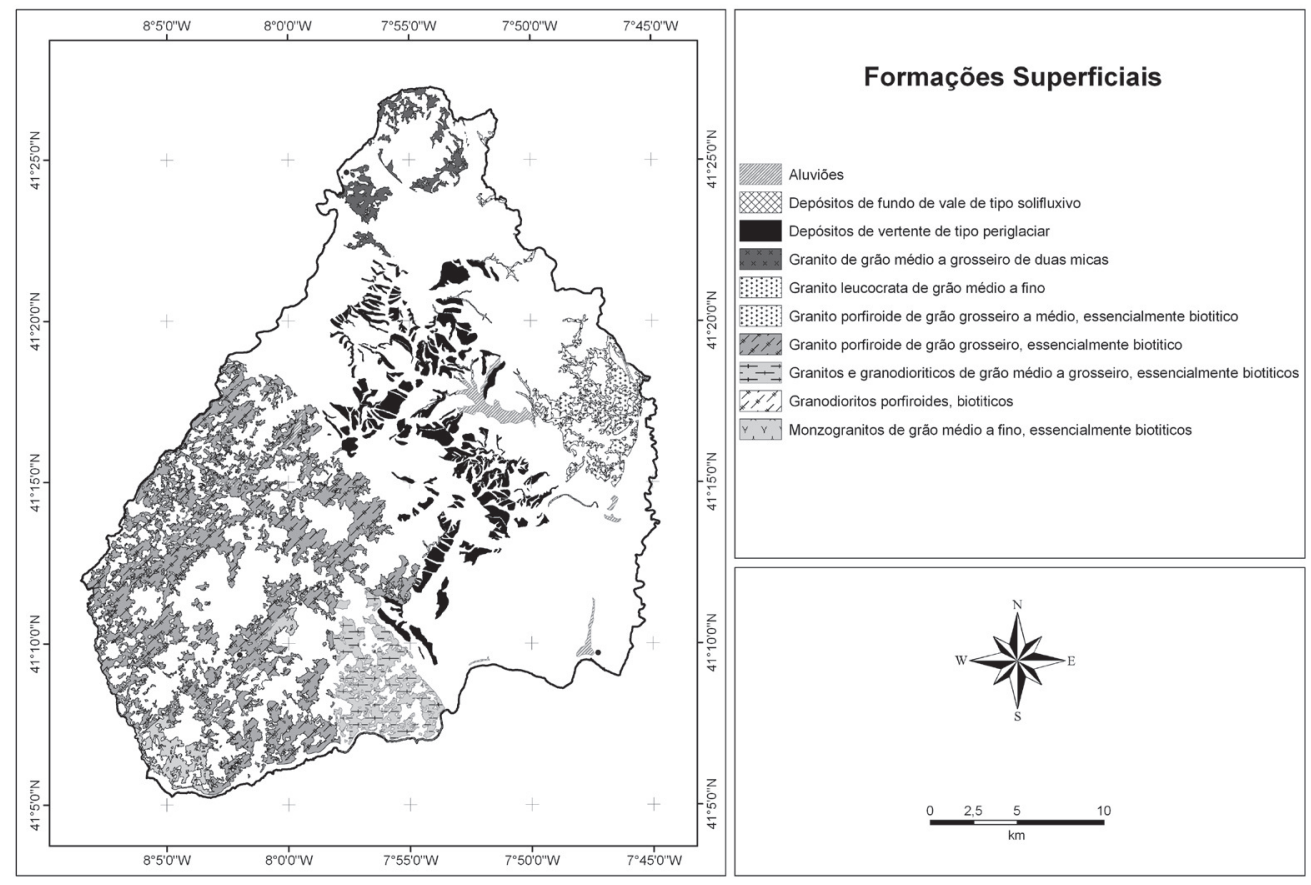

(MAP - Mantos de alteração profundos; MAS - Mantos de alteração superficiais) 


\section{CARTOGRAFIA DA SUSCEPTIBILIDADE GE- OMORFOLÓGICA AOS MOVIMENTOS EM MASSA: CONSIDERAÇÕES FINAIS.}

O mapa de susceptibilidade que resultou da aplicação deste modelo ou matriz de interpretação / previsão (Figura 4) classifica em quatro graus distintos a probabilidade de ocorrência de movimentos em massa na Serra do Marão, sendo a sua distribuição espacial coincidente com o conhecimento empírico do território, demonstrado em numerosos trabalhos de investigação prévios, que adoptaram uma abordagem interpretativa de estudos de caso concretos (PEDROSA, 1993, 1994 a 1994 , 2001; PEDROSA; MARQUES; 1994; PEDROSA, et al., 1995; PEDROSA; LOURENÇO; FELGUEIRAS, 2001; PEDROSA et al., 2007 ).

Salienta-se o grau de susceptibilidade elevado a muito elevado que afecta as vertentes com fortes declives associados à existência de formações superficiais, assim como as vertentes instabilizadas pelas intervenções e actividades antrópicas, com especial relevo para a cultura da vinha e para as áreas de agricultura tradicional dominadas pelas culturas de regadio, que ocupam solos profundos, resultantes da forte meteorização das rochas granitóides. Não se enquadra no espaço dedicado a este artigo, uma interpretação mais detalhada da expressão cartográfica da susceptibilidade, cujas nuances reflectem diversas especificidades locais que o modelo captou com fidelidade.

Figura 4: Cartografia da susceptibilidade geomorfológica aos movimentos em massa.

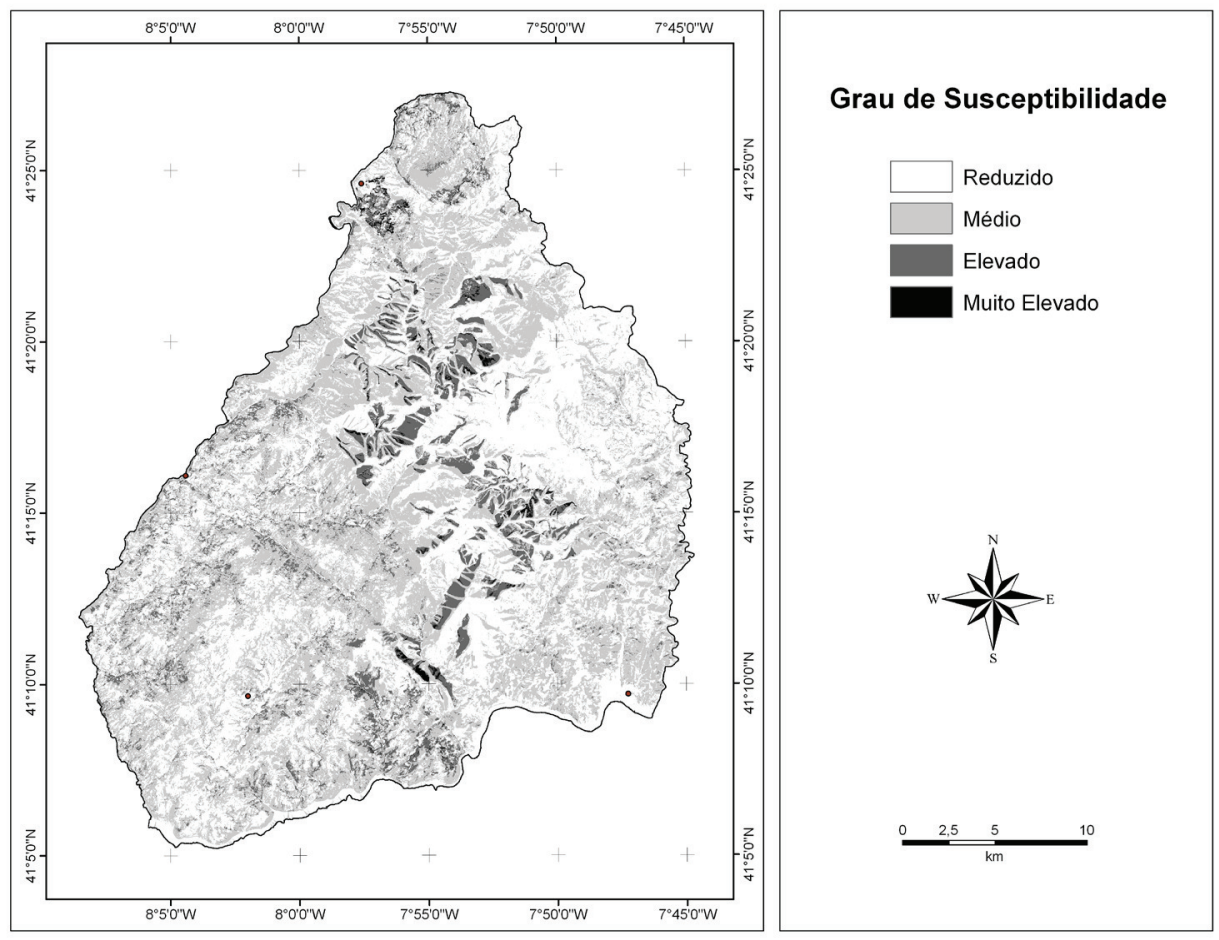

Saliente-se ainda que este ensaio demonstrou cabalmente que os declives, os mantos de alteração, os depósitos de vertente e as escombreiras de gravidade são fundamentais para explicar a susceptibilidade territorial aos movimentos em massa. Note-se, a este respeito, que as características litológicas, mesmo quando associadas a fortes declives, não explicam a forte susceptibilidade das vertentes de xisto a este tipo de processos na Serra no Marão. È a existência disseminada de depósitos periglaciares e tardiglaciares que explica, a maioria das vezes, a ocorrência de movimentos em massa, como se pode constatar na Figura 4. 
O trabalho de investigação aqui apresentado reflecte um percurso pessoal de maturação e evolução científica empreendido ao longo dos últimos 15 anos sobre a compreensão da dinâmica de vertentes no Norte de Portugal, coadjuvado pelo progresso da técnica materializado no notável desenvolvimento dos instrumentos e programas de geoprocessamento.

Reflectindo sobre os resultados alcançados presentemente neste domínio, parece-me imprescindível alertar, uma vez mais, para a necessidade premente de se proceder a um levantamento rigoroso e sistematizado das formações superficiais em Portugal, a fim de proporcionar à comunidade científica nacional um dado crucial à elaboração de uma cartografia do risco geomorfológico fiável e útil à gestão territorial.

\section{REFERÊNCIAS}

CORDEIRO, A. R. Nota preliminar sobre as formas e formações periglaciares na Serra da Freita, Cadernos de Geografia, v. 5, Coimbra, p. 161-172, 1986.

CORDEIRO, A. R. Evolução das vertentes da Serra da Freita no Quaternário recente, Cadernos de Geografia, v. 7, Coimbra, p. 87-133, 1988.

CORDEIRO, A. R. O depósito de Varzielas (Serra do Caramulo): contribuição para o estudo do Tardiglaciar Würmiano em Portugal, Cadernos de Geografia, v. 9, Coimbra, p. 49-60, 1990.

DAVEAU, S. Quelques exemples d'évolution quaternaire des versants au Portugal, Finisterra, Lisboa, v. 15, n. 8, p. 5-47, 1973.

DAVEAU, S. Le périglaciaire d'altitude au Portugal, Colloque sur le périglaciaire d'altitude du domaine méditerranéen et abords, Association Géographoque d'Álsace, Strasbourg, p.63-78. 1978.
DAVEAU, S. Progressos recentes no conhecimento da evolução holocénica da cobertura vegetal, em Portugal e nas regiões vizinhas, Finisterra, Lisboa, v. 45 , n. 21 p. $101-115$.

DIAS, J. Minho, Trás-os-Montes, Haut-Douro, Congrés International de Géographie, Lisboa, 1949.

GARMENDIA, M. C. P. Dynamique de vegetation tardiglaciaire et holocene du Centre-Nord de l'Espagne d'après l'analyse pollinique, Thése en Sciences, spéc. Paleoécologie, de l'Université d'Aix-Marseille III. 1988.

GOUDIE, A. Environmental Change, Clarendon Press, Oxford. 1979.

GUILLEN, Y. et al. () - Les climats et les hommes en Europe et en Afrique septentrional de $28000 \mathrm{BP}$ à 10000 BP, Bull. Assoc. Fr. Etud. Quatern., v. 4 n. 15, p. 187-193, 1978.

JORDA, M. Morphogenèse et évolution des paysages dans les Alpes de Haute Provence depuis le Tardiglaciaire: facteurs naturels et facteurs anthropiques, Bull. Assoc. Géog. Fr., p. 75-81, 1980.

NONN, H. Les regions côtières de la Galice (Espagne): Étude geomorphologique, Thése Lettres, Pub. Fac. Lettres, Unv. Strasbourg, Strasbourg. 1966.

PEDROSA, A. Um caso particular de erosão dos granitos na Serra do Marão, Cadernos de Geografia, $n^{\circ}$ 10, Coimbra, IEG, 1991, p. 537-549.

PEDROSA, A. Alguns processos erosivos: o exemplo de um pequeno afloramento granítico da Serra do Marão in Cuadernos do Laboratorio Xeológico de Laxe, O Castro, n. 17, 1992, 107-120. 
A integração das formações superficiais na modelação e cartografia do risco geormorfológico: o caso da Serra do Marão António de Sousa Pedrosa, Andreia Pereira

PEDROSA, A. Serra do Marão: Estudo de geomorfologia, Dissertação de Doutoramento, Faculdade de Letras da Universidade. do Porto, Porto. 1993. 495 p.

PEDROSA, A. Contributo para o conhecimento da dinâmca geomorfológica das serras do Norte de Portugal. O exemplo da serra do Marão, Rurália, Arouca, 1994a p. 69-90.

PEDROSA, A. As actividades humanas e os processos morfológicos. O exemplo da Serra do Marão, Territorium, Coimbra, 1994b . p. 23-34.

PEDROSA, A. O Periglaciar no Norte de Portugal: O estado actual dos conhecimentos, Periglaciarismo en la Península Ibérica, Canaria y Baleares, Granada, $1994^{c}$. p. $55-73$.

PEDROSA, A. Movimentos em massa e ordenamento do território, in Actas do II Seminário sobre Recursos Naturais, Ambiente e Ordenamento do Território, Vila Real, CF-7-11. 2001.

PEDROSA, A. et al. Covelo do Gerês: Contribuição para o estudo dos movimentos de massa no Norte de Portugal, Territorium, 2, Coimbra, p. 21-32, 1995.

PEDROSA, A. et al. Metodologia para o estudo dos ravinamentos, Metodologias de Estudo de Processos de Erosão, FLUP, Porto, 2001. p. 85-98.

PEDROSA, A. et al. Processos de erosão acelerada na Região Demarcada do Douro: um património em risco in Actas do $2^{\circ}$ Encontro Internacional: História da vinha e do vinho no vale do Douro, Estudos Documentos 17, Porto, Vila Real, Régua, S. João da Pesqueira, Instituto dos Vinhos do Douro e Porto, Universidade do Porto, Universidade de Trás-os-Montes e Alto Douro, Outubro, 2004. p. 213-235.
PEDROSA, A.; et al. Quaternary evolution of the Serra do Marão and its consequences in the present dynamics, Territorium, Revista da Associação Portuguesa de Riscos, Prevenção e Segurança, n. 14, 2007. p. 33-43. Disponível em: http://www.pluridoc.com/Site/ FrontOffice/default.aspx?module=Files/File Description

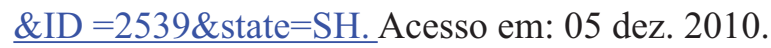

PEDROSA, A.; LOURENÇO, L.; FELGUEIRAS, J. (2001) - Movimentos em massa: exemplos ocorridos no Norte de Portugal Revista Técnica e Formativa da Escola Nacional de Bombeiros, v. 5, n. 17, p. 25-39

PEDROSA, A.; MARQUES, B. Serpa Man's action and slope erosion: A case study in Tâmega Basin (1981), Territorium, 1, Coimbra, p. 23-34. 1994.

PEDROSA, A.; PEREIRA, A. A Geografia e as Novas Estratégias de Desenvolvimento de Territórios Periféricos, in edição especial da revista Geografia. Ensino \& Pesquisa (Anais do V Seminário Latino-Americano e I Ibero-Americano de Geografia Física - Eixo 2, Santa Maria, v. 12 n. 1, p. 151-178. 2008. Disponível em: http://www.pluridoc.com/Site/FrontOffice/default. asp $x$ ? odule $=$ Files $/$ FileDescription $\& I D=2520 \&$ state $=$ SH . Acesso em: 12 dez. 2010.

PEDROSA, A; MARTINS B. M. Os movimentos em massa e os depósitos de vertente em áreas metassedimentares: alguns exemplos no Norte de Portugal in Actas do II Seminário sobre Recursos Naturais, Ambiente e Ordenamento do Território, Vila Real, p. 161-169. 2001

PEREIRA, E. Carta Geológica de Portugal - Notícia explicativa da folha 10-A (Celorico de Basto), Serviços Geológicos de Portugal, Lisboa. 1989

PEREIRA,E. S. Estudo geológico-estrutural daregião de Celorico de Basto e sua interpretação geodinâmica,1987. 274 f. Tese (Doutoramento), FCUL, Lisboa, 1987. 
PEREIRA, E.; RIBEIRO, A. Tectónica do sector noroeste da Serra do Marão, Comnu. Serv. Geol. Portugal, t. 69 , fasc. 2, p. 283-290. 1983.

REBELO, F. Serras de Valongo: estudo de Geomorfologia, Suplementos de Biblos, 9, Coimbra. 1975.

REBELO, F. Modelado periglaciar de baixa altitude em Portugal, Cadernos de Geografia, 5, Coimbra, 1986. p. 127-137.

REBELO, F; PEDROSA, A. Novas observações sobre depósitos relacionados com o frio na área de Valongo - S. Miguel-o-Anjo, El Cuaternario en Espana y Portugal, Madrid, v. 2, p. 501-504, 1993.

REBELO, V. A importância do Estudo dos Riscos Geomorfológicos no Ordenamento do concelho de Vieira do Minho. 2007. Dissertação (Mestrado em Gestão de Riscos Naturais), Faculdade de Letras da Universidade de Porto, Porto. 2007.

RIBEIRO, A. et al., Nota sobre a geologia da serra do Marão, Boletim da Sociedade Geológica de Portugal, v. 14, p-151-170, 1962.

SOUSA, B. Litostratigrafia e estrutura do "Complexo Xisto-Grauváquico ante-Ordovícico" - Grupo do Douro. 1982. Tese (Doutoramento), Universidade de Coimbra, Coimbra. 1982.

VLIRT - LANÖE, B. Le role de la glace de ségrégation dans les formations superficielles de l'Europe de l'Ouest. Processus et héritages. 1988. 854 f. Thèses (Doctorat d'Etat Mens. Géographie), Univ. Paris I, tome 1 et 2, Caen, 1988. 